\title{
Perioperative Management of Patients on Buprenorphine and Methadone: A Narrative Review
}

\author{
Yasmin Sritapan, Sean Clifford, Alexander Bautista
}

Department of Anesthesiology and Perioperative Medicine, University of Louisville, Louisville, Kentucky, USA

The opioid epidemic has emerged as a major health and social problem over the last few decades. An increasing number of patients with opioid use disorder are presenting for perioperative management. These patients are either on buprenorphine or methadone for the maintenance and treatment of opioid addiction or chronic pain. In the settings of acute pain, the optimal management of patients with opioid use disorder is challenging, and recovery can be jeopardized secondary to the unique pharmacology of these agents. The purpose of this narrative review is to summarize the existing studies on the perioperative management of patients who are using buprenorphine and methadone and provide guidance for the management of patients with opioid use disorder during the perioperative period.

Keywords: Buprenorphine, chronic pain, methadone, opioid use disorder, perioperative management, surgery
In 2016, an estimated 50 million adults in the United States struggled with chronic pain. (1) The chronic pain dilemma has led to a rapid increase in the use of opioid analgesics, which subsequently resulted in a greater number of overdose deaths due to opioid misuse. In 2018, according to the Department of Health and Human Services, two million people in the United States had opioid use disorder (OUD) and an estimated 130 people died every day due to opioid overdose (2). Correspondingly, different states have promulgated regulations on safe prescription by limiting the amount of opioid prescription and initiating online prescription-monitoring programs to address the misuse of opioid analgesics (3).

Medications such as long-acting synthetic opioid methadone and partial opioid agonist buprenorphine have been found to be the effective treatments for OUDs. These medications aim to decrease the illicit opioid use and relapse and increase treatment engagement $(4,5)$. It is paramount that these medications be continued at all times and not stopped prematurely (4). Therefore, it is essential that anesthesia providers know how to care for these potential patients in the perioperative period. Although there have been several institutionalized guidelines and pain management strategies to help these patients, there is still a lack of standardization and paucity of data to guide providers in addressing perioperative care for patients. The purpose of this narrative review is to discuss the pharmacologic profiles of buprenorphine and methadone in relation to OUDs and maintenance, highlight the existing literature on the perioperative management of patients with OUDs, and summarize recommendations for the optimal care of this subset of patients in hopes to help the guide providers in developing anesthetic regimen to optimize patient care.

\section{PHARMACOLOGY Of BUPRENORHINE}

Buprenorphine is a derivative of thebaine, which is a mixed opioid receptor modulator. It is highly lipophilic and has a large distribution volume (6). Its activity occurs at multiple receptor types. It is a partial agonist at the mu opioid receptor, which has an analgesic effect. As compared to other opioids, buprenorphine has a strong binding affinity to the mu opioid receptor with a slow dissociation from the receptor (7). Buprenorphine is also an antagonist at the kappa opioid receptor, which has been linked in the treatment of depression (7). Some patients who have been resistant to the standard treatment modalities for depression have responded positively to buprenorphine therapy. Buprenorphine's ability to limit the psychomimetic, euphoric, and induced hyperalgesia effects as compared to other opioids has been attributed to its kappa receptor antagonism (8). Additionally, buprenorphine is an agonist at the delta receptor, and its effects are not clearly understood (7). Buprenorphine has low receptor-stimulating activity, despite having a high receptor affinity and binding capacity leading to less euphoria, respiratory depression, and sedation even in higher doses (9). At a minimum, $40 \%-50 \%$ of receptor occupancy is needed to abate withdrawal symptoms in opioid-dependent patients, thus causing concern as the traditional dosing of opioids may not be effective in providing analgesia in the perioperative period (10).

Buprenorphine's half-life is widely variable and depends on the route of administration. It is poorly absorbed by the gastrointestinal system; hence, it is administered via sublingual, dermal, and parenteral routes. Its half-life is three hours when it is administered via intravenous (IV) route and can be 24-60 hours when it is administered sublingually (11). It is metabolized by the liver and

\footnotetext{
Address for Correspondence: Yasmin Sritapan, Department of Anesthesiology and Perioperative Medicine, University of Louisville, Louisville, Kentucky, USA Phone: +3103820504 e-mail: yasmin.sritapan@louisville.edu ORCID: orcid.org/0000-0003-0051-3503

Received: 1 May $2020 \quad$ Accepted: 14 May 2020 •DOI: 10.4274/balkanmedj.galenos.2020.2020.5.2

Available at www.balkanmedicaljournal.org

Cite this article as:

Sritapan Y, Clifford S, Bautista A. Perioperative Management of Patients on Buprenorphine and Methadone: A Narrative Review. Balkan Med J 2020;37:247-52

${ }^{\circ}$ Copyright 2020 by Trakya University Faculty of Medicine / The Balkan Medical Journal published by Galenos Publishing House.
} 
the majority of it is excreted through bile (6). Buprenorphine has a quick onset of 30-60 minutes when it is administered sublingually and 5-15 minutes with IV administration (6). The usual dose of buprenorphine ranges from 2 to 32 milligram per day $(\mathrm{mg} / \mathrm{d})$ and the maximum effect occurs the dose between 16 and $32 \mathrm{mg} / \mathrm{d}$ (12). It provides effective analgesia at low to moderate doses and is 30 times more potent than morphine. An IV dose of $0.3 \mathrm{mg}$ of buprenorphine is equivalent to approximately $10 \mathrm{mg}$ of morphine (13).

\section{PHARMACOLOGY of METHADONE}

Methadone is a long-acting synthetic opioid that is a full mu receptor agonist. It has been used both as an analgesic in severe pain and in the treatment of OUDs. When used for the treatment of OUD, the oral stock solution is often mixed with orange-colored solution or cherry syrup to prevent the aberrant use through the parenteral route. It is rapidly absorbed following oral administration, and its effects start between 15 and 45 minutes with a maximum plasma concentration of 2.5-4 hours after administration. Methadone is widely distributed in the body and it is highly bound to protein leading to cumulative effect and slow elimination (14). It has a long but variable half-life with mean estimates varying from 15 to 55 hours (15). Methadone undergoes biotransformation rather than conjugation in the liver, and its metabolites are cleared via the fecal route. (16) The accumulation of methadone in the system may lead to sedation and respiratory depression, especially upon the initiation of therapy (17).

An effective daily dose of methadone for OUDs varies between 60 and $120 \mathrm{mg} / \mathrm{d}$ (17). The purpose of high doses is to suppress the withdrawal symptoms and eliminate cravings with minimal side effects. Patients on a higher dose may develop a prolonged QT interval, which could lead to the development of torsade de pointes, especially if co-administered with drugs that inherently prolong QT (18). It is important to note that a daily methadone dose for the treatment of OUD is inadequate in providing acute pain relief, and additional medications and strategies are often required to mitigate the pain (19).

\section{SUMMARY of EVIDENCE}

Current studies related to the use of buprenorphine and methadone for patients with OUDs presenting for surgery are mostly retrospective reviews, case reports, case series, and expert opinions. Table 1 provides a summary of these published studies.

\section{Summary of evidence for buprenorphine}

Buprenorphine has several advantages over methadone for the treatment of OUDs. It was shown to have less potential for abuse, provides greater flexibility in prescribing, and can be managed as an office-based treatment option (20). Therefore, there is an increased utilization of buprenorphine for OUD treatment.

There are several strategies proposed to treat severe pain in patients on buprenorphine maintenance treatment. When planning to continue buprenorphine during the perioperative period (especially in emergent and major surgeries), it is advised to use the different types of oral opioids and/or IV opioid analgesics with the use of patient-controlled analgesia (PCA) titrated for adequate pain control $(21,22)$. A study showed that patients on buprenorphine may often require higher doses of opioids to displace the avidly bound buprenorphine from the mu opioid receptors and pain control can be adequately achieved (23). Alternatively, buprenorphine can be transitioned to full opioid agonists three to five days before elective procedures to avoid the challenges of poorly controlled pain (24). A multimodal pain management approach with the use of dexmedetomidine, remifentanil, and ketamine perioperatively has shown success in providing adequate pain control among patients taking buprenorphine for OUD $(25,26)$. The use of regional anesthesia, though reasonable, was inconsistent in terms of decreasing the amount of opioid used in the perioperative period in one case series (25). In patients who are on a low dose of buprenorphine, that is 2-8 $\mathrm{mg}$ per day, buprenorphine can be continued as an analgesic by increasing the frequency of the dose in every 6-8 hours (21). In patients who will not be able to tolerate sublingual buprenorphine, buprenorphine can be discontinued 72 hours before surgery and replaced with full mu opioid agonist for the titration of analgesia (21). If the risk of relapse is high, then buprenorphine can be replaced with methadone by using a modified dosing ratio of 1:5, respectively, and titrated to achieve adequate pain relief (21).

\section{Summary of evidence for methadone}

Researchers have proposed algorithms for managing patients on methadone presenting for elective surgery. If the patient can tolerate oral medication, then it is advised to continue oral methadone on the morning of surgery and throughout the perioperative period $(16,21,27)$. If the patient is unable to do so, then methadone can be dosed parenterally at a dose half to two-thirds of the maintenance dose divided into two to four equal doses a day (21). In situations when methadone is not available, the conversion of methadone to any opioid can be performed; however, the conversion calculations may not be bidirectional due to the long half-life of methadone (21). A multimodal approach $(16,27)$ including the perioperative infusion of ketamine (28-30), clonidine (31), and the use of regional anesthesia (32) should be considered. In a retrospective cohort study performed by Macintyre et al. (26), methadone opioid substitution therapy was continued and it showed the efficacy and safety of PCA opioids for the management of postoperative pain (26). Nevertheless, caution is strongly advised while continuing methadone in specific surgeries such as bariatric as the serum levels of methadone can increase post-operatively (33).

\section{DISCUSSION}

The perioperative management of patients with OUD is complex. These patients may have underlying medical, psychiatric, surgical conditions, and psychosocial problems in conjunction with their medication treatment. The management of their pain in the acute setting following surgery can be challenging and, often times, their OUD is not addressed. This may result with the worsening of their medical condition, readmission rates, overdose, and relapse. These patients require specific considerations and planning to prevent poor outcomes. 


\section{Preoperative considerations}

The stigma associated with OUDs may foster a negative judgment of the patient. These patients can be perceived as drug-seekers if their pain is poorly controlled. In this regard, patients worry about receiving inappropriate care in terms of pain control with the possibility of relapse and withdrawal symptoms.

It is recommended that these patients be evaluated preoperatively to obtain a full pain history, physical examination, and assessment for other psychiatric and medical comorbidities (34). It is imperative to take a detailed medication history that includes dose, frequency of ingestion, time of last dose, and assessment of the level of treatment stability (16). A urine toxicology screening provides useful information regarding medication compliance as well as the use of illicit drugs or medications beyond the agreement with their prescription provider. Opioid-monitoring databases should be accessed to review for controlled substance prescription. It is also prudent to reach out to the patient's prescription provider to discuss the pain management strategy in the acute perioperative setting as well as arrange follow-up(s) for the continuation of maintenance therapy. The consultation of an in-house addiction specialist may be considered to provide support before and after the surgery. During the preoperative period, it is important to establish goals of care with the patient, which addresses realistic goals for pain management, the challenges of acute pain management as well as the concern and risk of relapse following the reinstitution of opioid therapy. It is important to educate patients and their family regarding the risk of relapse and appropriate management of anxiety, craving, and pain.

\section{Intraoperative considerations}

It is important to understand that patients receiving maintenance therapy with buprenorphine and methadone do not receive adequate analgesia from these opioids in the setting of acute pain. The analgesic and addiction profile treatment differ as well as the associated neuroplastic changes associated with long-term opioid exposure, that is, tolerance and hyperalgesia may effectively diminish their analgesic properties (35). For example, in patients receiving methadone as maintenance therapy, the analgesic effect of morphine did not last as long as expected due to cross-tolerance (36). Patients also have significantly higher opioid requirements and a prolonged length of stay $(23,37)$. This was echoed with a patient on buprenorphine therapy, who had poor pain control in the perioperative period in two different gynecological surgeries where buprenorphine was continued in the first and transitioned to full opioid agonist in the second (38). It may be beneficial to use regional anesthesia when possible and multimodal analgesic combinations to target pain pathways at different sites to provide superior pain relief and decreased opioid consumption.

\section{Postoperative considerations}

The patient's baseline addiction treatment needs to be addressed during the treatment of acute pain while taking maintenance buprenorphine and methadone therapy. It is imperative to have a plan for aggressive pain management (39). The undertreatment of pain predisposes patients to decreased opioid responsiveness, which can lead to difficulty in controlling pain (40). Analgesics including nonsteroidal anti-inflammatory drugs, acetaminophen, and adjuvant analgesics that can enhance opioid effects such as gabapentinoids and ketamine may be used together in a multimodal approach to improve the pain control (41-43).

If the decision is made to continue the use of methadone and buprenorphine, then it is important to continue the patient's usual dose to avoid the worsening of pain symptoms due to increased pain sensitivity associated with opioid withdrawal (44). Adequate pain control would require the administration of a higher dose of opioid analgesic that should be continuous or scheduled, instead of prescribing it on a needed basis (39). The use of PCA was found to be helpful via increased control over analgesia and minimization of patient anxiety about pain management $(45,46)$.

Regarding methadone, if the patient is unable to receive oral medications, then methadone dose can be administered via IV, intramuscular (IM) or subcutaneous (SC) routes. The dosing methadone via IV, IM and SC routes should be administered as half to two-thirds of the maintenance dose divided into two to four equal doses (47).

The high affinity of buprenorphine to the mu receptor makes pain treatment more complicated than methadone. The most effective approach comes with the clinical experience of the provider with buprenorphine. The upward titration of a short-acting full opioid agonist to effect is recommended if the decision is to continue buprenorphine in the perioperative period. The buprenorphine dose can also be increased in patients who are not on a maximal dose to 24-32 mg daily (20). Strategies that involve dividing the daily doses of buprenorphine to every six to eight hours have been discussed. A 0.4-mg dose of buprenorphine administered sublingually every eight hours may be adequate in patients who are opioid naïve (13). If the decision is made to discontinue buprenorphine therapy, then the patient should be treated with full opioid analgesics and withdrawal should be avoided (6). These patients should follow-up with the OUD provider in the postoperative period to resume maintenance therapy by using an induction protocol after the resolution of acute pain. Another strategy is to convert buprenorphine to methadone to prevent acute withdrawal (39).

\section{Summary of recommendations}

Figure 1 outlines the authors' recommendations in the management of patients with OUD. Patients with OUD should be seen in the preoperative clinic before the elective surgery to obtain: medical and pain history, medication dosage, and to better understand the patient's support system outside of the hospital setting. In the setting of urgent or emergent surgeries, the same information and care discussion should be addressed before surgery if time permits. The ultimate goal is to achieve adequate pain management in patients with OUD receiving buprenorphine and methadone. We recommend continuing patients' buprenorphine and methadone regimen in the perioperative setting with the understanding that patient may require higher amounts of opioid agonist. Our recommendation differs from other narrative reviews, which provide the option of discontinuing buprenorphine or methadone in the perioperative setting (43). Furthermore, multimodal analgesic 
TABLE 1. Summary of current studies published relating to the use of buprenorphine and methadone in patients with opioid use disorder presenting for surgery

\begin{tabular}{|c|c|c|c|c|}
\hline & Authors & Year & Study type & Key findings \\
\hline \multirow{2}{*}{ 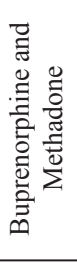 } & $\begin{array}{l}\text { Hansen et al. } \\
(23)\end{array}$ & 2016 & $\begin{array}{l}\text { Prospective matched cohort } \\
\text { study }\end{array}$ & $\begin{array}{l}\text { - Dose of oral narcotics was higher at discharge in patients maintained on methadone or BUP/ } \\
\text { NAL in the perioperative period } \\
\text { - No difference in pain scores on day of surgery, post-op day } 1 \text {, and on post-op day } 2 \text { between } \\
\text { the study and control group }\end{array}$ \\
\hline & $\begin{array}{l}\text { Macintyre et al. } \\
(26)\end{array}$ & 2013 & Retrospective cohort study & $\begin{array}{l}\text { - Patients who did not receive their buprenorphine the day after surgery significantly required } \\
\text { more PCA opioid relative to the patients that received their buprenorphine the day after } \\
\text { surgery }\end{array}$ \\
\hline \multirow{14}{*}{ 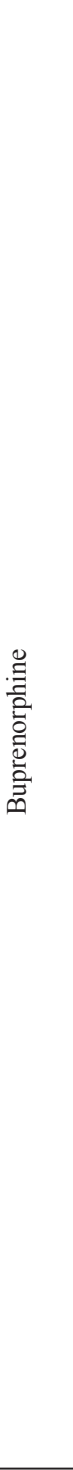 } & Martin et al. (8) & 2019 & Retrospective matched study & $\begin{array}{l}\text { - Patients treated with TdBUP received higher doses of intraoperative opioids than patients } \\
\text { who are opioid naïve } \\
\text { - Postoperative opioid requirement had a linear correlation with preoperative TdBUP dosing } \\
\text { - Preoperative pain scores were higher among patients on TdBUP } \\
\text { - No difference in Phase I recovery pain scores between the groups }\end{array}$ \\
\hline & Martin et al. (25) & 2019 & Retrospective observation & $\begin{array}{l}\text { - No difference in opioid requirements during the perioperative period between combined and } \\
\text { general anesthesia among patients maintained on SL-BUP } \\
\text { - No difference in opioid requirement between patients who continued SL-BUP on day of } \\
\text { surgery vs stopping SL-BUP }\end{array}$ \\
\hline & $\begin{array}{l}\text { Silva and } \\
\text { Rubinstein (48) }\end{array}$ & 2016 & Case report & $\begin{array}{l}\text { - First surgery: patient was maintained on SL-BUP in the perioperative period and had } \\
\text { adequate pain control with multimodal pain approach }\end{array}$ \\
\hline & & & $\begin{array}{l}\text { Comparing two different } \\
\text { outcomes for one patient } \\
\text { undergoing two similar } \\
\text { surgeries (knee arthroplasty) }\end{array}$ & $\begin{array}{l}\text { - Second surgery: patient was not on SL-BUP and required increased pain medication in the } \\
\text { postoperative period and required increased morphine equivalent at discharge as compared } \\
\text { to first surgery }\end{array}$ \\
\hline & Huang et al. (49) & 2014 & Case report & $\begin{array}{l}\text { - } 16 \mathrm{mg} \text { of suboxone (BUP/NAL) twice a day was continued perioperatively } \\
\text { - Ineffective postoperative pain management } \\
\text { - Pain control was improved after tapering suboxone }\end{array}$ \\
\hline & $\begin{array}{l}\text { Khelemsky et al. } \\
\text { (50) }\end{array}$ & 2015 & & $\begin{array}{l}\text { - Unable to prevent intraoperative movement in patient undergoing cervical spine surgery } \\
\text { while on Buprenorphine }\end{array}$ \\
\hline & & & $\begin{array}{l}\text { One patient undergoing } 2 \\
\text { similar procedure }\end{array}$ & $\begin{array}{l}\text { - Prevention of intraoperative movement was achieved in the first surgery after the addition } \\
\text { of ketamine }\end{array}$ \\
\hline & & & & $\begin{array}{l}\text { - Five days later, after the cessation of buprenorphine, during second cervical spine surgery, } \\
\text { the patient had decreased anesthetic requirement, and the prevention of intraoperative } \\
\text { movement was achieved without ketamine }\end{array}$ \\
\hline & $\begin{array}{l}\text { McCormick et } \\
\text { al. }(22)\end{array}$ & 2013 & Case report & $\begin{array}{l}\text { - Pain control was a challenge in a patient with McArdle Disease on BUP/NAL undergoing } \\
\text { emergent bilateral fasciotomies }\end{array}$ \\
\hline & & & & - Required increased hydromorphone PCA requirement in the perioperative period \\
\hline & Chern et al. (38) & 2013 & Case report & - Poor pain control in both procedures \\
\hline & & & $\begin{array}{l}\text { Two separate } \\
\text { urogynecological procedure } \\
\text { in a patient with Type I } \\
\text { Chiari Malformation }\end{array}$ & $\begin{array}{l}\text { - In first procedure, } 8 \mathrm{mg} \text { of SL-BUP three times a day was continued up to the day of surgery } \\
\text { with supplemental full opioids in the postoperative period } \\
\text { - In second procedure, SL-BUP was switched to full agonist five days before procedure and } \\
\text { postoperative pain was managed with full opioid receptor agonists }\end{array}$ \\
\hline & $\begin{array}{l}\text { Kornfeld and } \\
\text { Manfredi (51) }\end{array}$ & 2010 & Case series & $\begin{array}{l}\text { - Five patients who underwent seven procedures maintained on SL-BUP } \\
\text { - Majority of the patients had uninterrupted SL-BUP treatment during the hospital stay } \\
\text { - All patients had good post-op pain control }\end{array}$ \\
\hline & $\begin{array}{l}\text { Brummett et al. } \\
(24)\end{array}$ & 2009 & Case report & $\begin{array}{l}\text { - Patient maintained on } 16 \mathrm{mg} \text { of SL-BUP, which was continued on day of surgery, had high } \\
\text { requirements of morphine PCA, which was not sufficient for adequate pain control, after } \\
\text { L3-L5 spinal fusion. Adequate post-op pain was finally achieved with dexmedetomidine drip }\end{array}$ \\
\hline \multirow{5}{*}{ 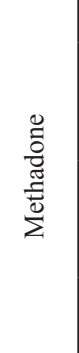 } & Barelli et al. (28) & 2019 & Case report & - Ketamine can reduce opioid requirements in a patient maintained on methadone \\
\hline & Chan et al. (37) & 2017 & Retrospective matched & $\begin{array}{l}\text { - Patients on chronic methadone required significantly increased amount of opioid in the } \\
\text { perioperative period as compared to patients not on methadone }\end{array}$ \\
\hline & & & & - Patients on methadone had a longer length of hospital stay \\
\hline & $\begin{array}{l}\text { Strommen et al. } \\
\text { (33) }\end{array}$ & 2016 & Case report & $\begin{array}{l}\text { - Methadone was continued during bariatric surgery } \\
\text { - Caution needs to be taken on methadone dose in bariatric patient as blood concentration can } \\
\text { increase during the postoperative period }\end{array}$ \\
\hline & Kaye et al. (30) & 2014 & Case report & $\begin{array}{l}\text { - Patient on methadone for leiomyosarcoma required a multimodal approach with clonidine } \\
\text { and ketamine for successful pain management }\end{array}$ \\
\hline
\end{tabular}




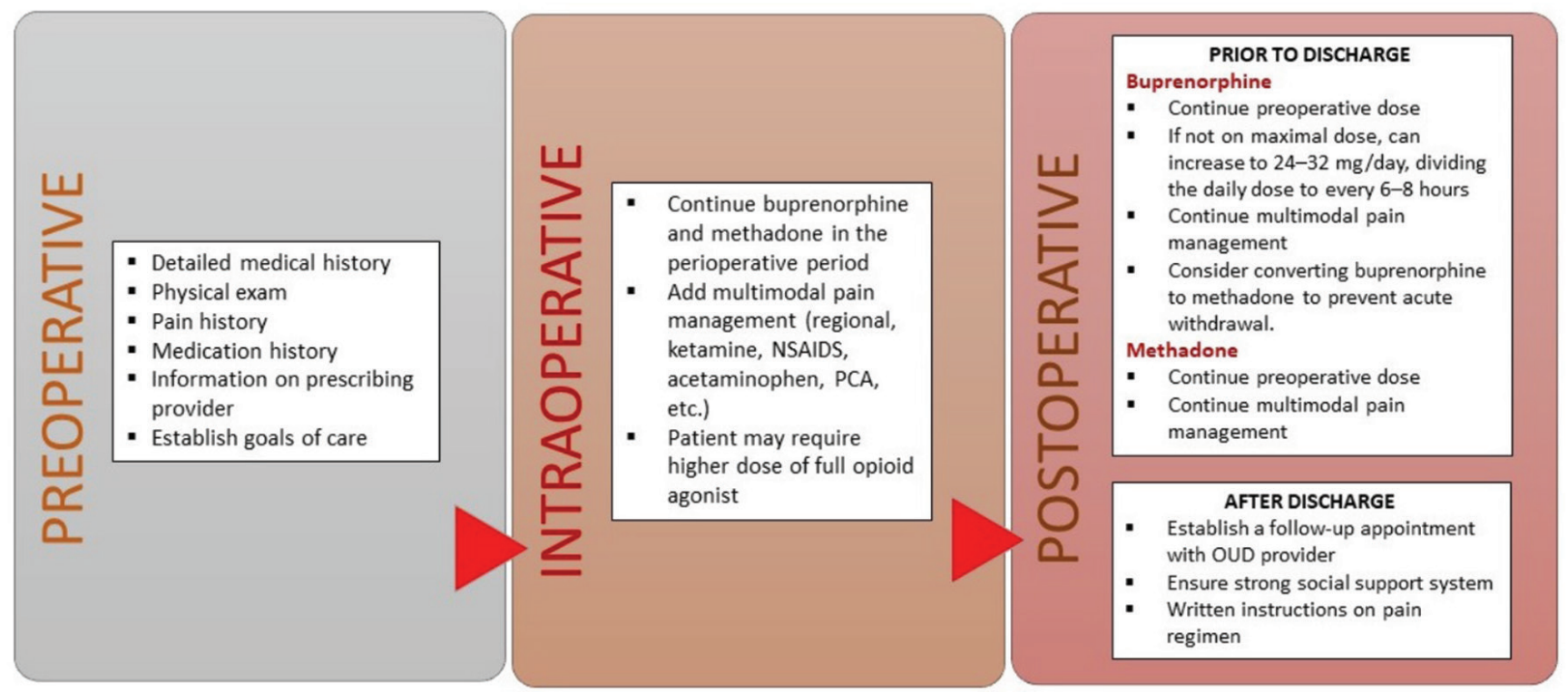

FIG. 1. Outline of recommendation for the management of patients presenting for surgery with opioid use disorder.

strategies that incorporate the use of nonsteroidal anti-inflammatory drugs, acetaminophen, gabapentinoids, ketamine, alpha 2 agonist, and regional anesthesia should be utilized to achieve adequate pain management. Postoperative plan should be prepared before discharge, which incorporates written pain management regimen after discharge and follow-up with their outpatient provider of buprenorphine and methadone.

In conclusion, the increasing utilization of buprenorphine and methadone as a maintenance therapy for OUDs continues to grow to fight against the opioid epidemic. As a result, these patients face challenges in acute pain management during the perioperative period. These complex patients have altered the neural responses of tolerance and hyperalgesia that may alter and worsen the pain experience. Management with a traditional dosing of mu receptor opioid analgesics may be inadequate during the perioperative period. Moreover, patients may require higher doses of opioids with an inherent risk of precipitating patient cravings and subsequent relapse. Therefore, multimodal strategies should be employed as a part of the aggressive pain management to mitigate anxiety and allow for the successful treatment of pain. The author's recommendation to continue buprenorphine and methadone was based on the strength of evidence and personal experience. However, providers should be cognizant of the fact that pain is subjective and treatment needs to be individualized.

Conflict of Interest: No conflict of interest was declared by the authors.

Financial Disclosure: No financial disclosure was declared by the authors.

\section{REFERENCES}

1. Dahlhamer J, Lucas J, Zelaya C, Nahin R, Mackey S, DeBar L, et al. Prevalence of Chronic Pain and High Impact Chronic Pain Among Adults - United States 2016. MMWR Morb Mortal Wkly Rep. 2018;67:1001-6

2. US Department of Health and Human Services, accessed 22 January 2020, https:// www.hhs.gov/opioids
3. National Governors Association. A Compact to Fight Opioid Addiction. 2016, accessed 30 March 2020, https:/www.nga.org/wp-content/uploads/2019/01/NGAOpioid-Compact-State-Reporting-Chart-003.pdf

4. Sordo L, Barrio G, Bravo MJ, Indave BI, Degenhardt L, Wiessing L, et al. Mortality risk during and after opioid substitution treatment: systematic review and metaanalysis of cohort studies. BMJ 2017;357:j1550.

5. Nielsen S, Larance B, Degenhardt L, Gowing L, Kehler C, Lintzeris N. Opioid agonist treatment for pharmaceutical opioid dependent people. Cochrane Database Syst Rev 2016:CD011117.

6. Jonan AB, Kaye AD, Urman RD. Buprenorphine Formulations: Clinical Best Practice Strategies Recommendations for Perioperative Management of Patients Undergoing Surgical or Interventional Pain Procedures. Pain Physician 2018;21:1-12.

7. Walsh SL, Preston KL, Stitzer ML, Cone EJ, Bigelow GE. Clinical pharmacology of buprenorphine: ceiling effects at high doses. Clin Pharmacol Ther 1994;55:56980 .

8. Martin YN, Pearson ACS, Tranchida JR, Weingarten TN, Schulte PJ, Sprung J. Implications of uninterrupted preoperative transdermal buprenorphine use on postoperative pain management. Reg Anesth Pain Med 2019 Jan 11;rapm-2018100018. doi: 10.1136/rapm-2018-100018. Online ahead of print.

9. Walsh SL, Eissenberg T. The clinical pharmacology of buprenorphine: extrapolating from the laboratory to the clinic. Drug Alcohol Depend 2003;70(2 Suppl):13-27.

10. Greenwald M, Johanson CE, Bueller J, Chang Y, Moody DE, Kilbourn M, et al. Buprenorphine duration of action: mu-opioid receptor availability and pharmacokinetic and behavioral indices. Biol Psychiatry 2007;61:101-10.

11. Elkader A, Sproule B. Buprenorphine: clinical pharmacokinetics in the treatment of opioid dependence. Clin Pharmacokinet 2005;44:661-80.

12. Johnson RE, Strain EC, Amass L. Buprenorphine: how to use it right. Drug Alcohol Depend 2003;70(2 Suppl):59-77.

13. Johnson RE, Fudala PJ, Payne R. Buprenorphine: considerations for pain management J Pain Symptom Manage 2005;29:297-326.

14. Corkery JM, Schifano F, Ghodse AH, Oyefeso A. The effects of methadone and its role in fatalities. Hum Psychopharmacol 2004;19:565-76.

15. Wolff K. Characterization of methadone overdose: clinical considerations and the scientific evidence. Ther Drug Monit 2002;24:457-70.

16. Peng PWH, Tumber PS, Gourlay D. Review article: perioperative pain management of patients on methadone therapy. Can J Anaesth 2005;52:513-23.

17. Dematteis M, Auriacombe M, D'Agnone O, Somaini L, Szerman N, Littlewood R, et al. Recommendations for buprenorphine and methadone therapy in opioid use disorder: a European consensus. Expert Opin Pharmacother 2017;18:1987-99. 
18. Krantz MJ, Lewkowiez L, Hays H, Woodroffe MA, Robertson AD, Mehler PS Torsade de pointes associated with very-high-dose methadone. Ann Intern Med 2002;137:501-4.

19. Ward EN, Quaye AN, Wilens TE. Opioid Use Disorders: Perioperative Management of a Special Population. Anesth Analg 2018;127:539-47.

20. Anderson TA, Quaye ANA, Ward EN, Wilens TE, Hilliard PE, Brummett CM. To Stop or Not, That Is the Question: Acute Pain Management for the Patient on Chronic Buprenorphine. Anesthesiology 2017;126:1180-6.

21. Coluzzi F, Bifulco F, Cuomo A, Dauri M, Leonardi C, Melotti RM, et al. The challenge of perioperative pain management in opioid-tolerant patients. Ther Clin Risk Manag 2017;13:1163-73.

22. McCormick Z, Chu SK, Chang-Chien GC, Joseph P. Acute pain control challenges with buprenorphine/naloxone therapy in a patient with compartment syndrome secondary to McArdle's disease: a case report and review. Pain Med 2013;14:118791.

23. Hansen LE, Stone GL, Matson CA, Tybor DJ, Pevear ME, Smith EL. Total Joint Arthroplasty in Patients Taking Methadone or Buprenorphine/Naloxone Preoperatively for Prior Heroin Addiction: A Prospective Matched Cohort Study. J Arthroplasty 2016;31:1698-701.

24. Brummett CM, Trivedi KA, Dubovoy AV, Berland DW. Dexmedetomidine as a novel therapeutic for postoperative pain in a patient treated with buprenorphine. J Opioid Manag 2009;5:175-9.

25. Martin YN, Deljou A, Weingarten TN, Schroeder DR, Sprung J. Perioperative opioid requirements of patients receiving sublingual buprenorphine-naloxone: a case series BMC Anesthesiol 2019;19:68.

26. Macintyre PE, Russell RA, Usher KAN, Gaughwin M, Huxtable CA. Pain relief and opioid requirements in the first 24 hours after surgery in patients taking buprenorphine and methadone opioid substitution therapy. Anaesth Intensive Care 2013;41:222-30.

27. Cornett EM, Kline RJ, Robichaux SL, Green JB, Anyama BC, Gennuso SA, et al. Comprehensive Perioperative Management Considerations in Patients Taking Methadone. Curr Pain Headache Rep 2019;23:49.

28. Barelli R, Morelli Sbarra G, Sbaraglia F, Zappia L, Rossi M. Prevention of postoperative hyperalgesia in a heroin-addicted patient on methadone maintenance. J Clin Pharm Ther 2019;44:397-9.

29. Haller G, Waeber JL, Infante NK, Clergue F. Ketamine combined with morphine for the management of pain in an opioid addict. Anesthesiology 2002;96:1265-6.

30. Kaye AD, Alian AA, Vadivelu N, Chung KS. Perioperative dilemma: challenges of the management of a patient on mega doses of morphine and methadone. J Opioid Manag 2014;10:69-72

31. Gowing L, Ali R, White JM. Opioid antagonists with minimal sedation for opioid withdrawal. Cochrane Database Syst Rev 2017;5:CD002021.

32. May JA, White HC, Leonard-White A, Warltier DC, Pagel PS. The patient recovering from alcohol or drug addiction: special issues for the anesthesiologist. Anesth Analg 2001;92:1601-8.

33. Strommen M, Helland A, Kulseng B, Spigset O. Bioavailability of Methadone Afte Sleeve Gastrectomy: A Planned Case Observation. Clin Ther 2016;38:1532-6.
34. Committee on Standards and Practice Parameters, Apfelbaum JL, Connis RT, Nickinovich DG; American Society of Anesthesiologists Task Force on Preanesthesia Evaluation, Pasternak LR, Arens JF, Caplan RA, Connis RT, et al. Practice advisory for preanesthesia evaluation: an updated report by the American Society of Anesthesiologists Task Force on Preanesthesia Evaluation. Anesthesiology 2012;116:522-38

35. White JM. Pleasure into pain: the consequences of long-term opioid use. Addict Behav 2004;29:1311-24

36. Doverty M, Somogyi AA, White JM, Bochner F, Beare CH, Menelaou A, et al Methadone maintenance patients are cross-tolerant to the antinociceptive effects of morphine. Pain 2001;93:155-63.

37. Chan FJ, Schwartz AM, Wong J, Chen C, Tiwari B, Kim SJ. Use of Chronic Methadone Before Total Knee Arthroplasty. J Arthroplasty 2017;32:2105-7.

38. Chern SYS, Isserman R, Chen L, Ashburn M, Liu R. Perioperative Pain Management for Patients on Chronic Buprenorphine: A Case Report. J Anesth Clin Res 2013;3:1000250.

39. Alford DP, Compton P, Samet JH. Acute pain management for patients receiving maintenance methadone or buprenorphine therapy. Ann Intern Med 2006;144:127-34

40. Mao J, Price DD, Mayer DJ. Experimental mononeuropathy reduces the antinociceptive effects of morphine: implications for common intracellular mechanisms involved in morphine tolerance and neuropathic pain. Pain 1995;61:353-64.

41. Kehlet H, Dahl JB. The value of "multimodal" or "balanced analgesia" in postoperative pain treatment. Anesth Analg 1993;77:1048-56.

42. Weinbroum AA. Non-opioid IV adjuvants in the perioperative period: pharmacological and clinical aspects of ketamine and gabapentinoids. Pharmacol Res 2012;65:411-29.

43. Harrison TK, Kornfeld H, Aggarwal AK, Lembke A. Perioperative Considerations for the Patient with Opioid Use Disorder on Buprenorphine, Methadone, or Naltrexone Maintenance Therapy. Anesthesiol Clin 2018;36:345-59.

44. Jasinski DR. Tolerance and dependence to opiates. Acta Anaesthesiol Scand 1997;41:184-6.

45. Boyle RK. Intra- and postoperative anaesthetic management of an opioid addict undergoing caesarean section. Anaesth Intensive Care 1991;19:276-9.

46. Sevarino FB, Sinatra RS, Paige D, Silverman DG. Intravenous ketorolac as an adjunct to patient-controlled analgesia (PCA) for management of postgynecologic surgica pain. J Clin Anesth 1994;6:23-7.

47. Fishman SM, Wilsey B, Mahajan G, Molina P. Methadone reincarnated: novel clinical applications with related concerns. Pain Med 2002;3:339-48.

48. Silva MJ, Rubinstein A. Continuous Perioperative Sublingual Buprenorphine. J Pain Palliat Care Pharmacother 2016;30:289-93.

49. Huang A, Katznelson R, de Perrot M, Clarke H. Perioperative management of a patient undergoing Clagett window closure stabilized on Suboxone ${ }^{\circledR}$ for chronic pain: a case report. Can J Anaesth 2014;61:826-31.

50. Khelemsky Y, Schauer J, Loo N. Effect of buprenorphine on total intravenous anesthetic requirements during spine surgery. Pain Physician 2015;18:E261-E4.

51. Kornfeld H, Manfredi L. Effectiveness of full agonist opioids in patients stabilized on buprenorphine undergoing major surgery: a case series. Am J Ther 2010;17:523-8. 